\title{
Laboratory reference intervals for systolic blood pressure, rectal temperature, haematology, biochemistry and venous blood gas and electrolytes in healthy pet rabbits
}

\author{
Miguel Gallego* \\ Centro Veterinario Madrid Exóticos, Madrid, Spain
}

\begin{abstract}
Prospective data from 86 healthy pet rabbits were evaluated to establish reference intervals for hematology, biochemistry, urinalysis, venous blood gas and electrolytes, rectal temperature and systolic blood pressure. Reference intervals for rectal temperature $\left(37.4-39.6{ }^{\circ} \mathrm{C}\right)$ and systolic blood pressure $(75-134 \mathrm{~mm} / \mathrm{Hg}$ ) were previously unreported in pet rabbits. Differences by more than $30 \%$ with reference intervals present in the bibliography were observed in the blood biochemistry and urinalysis, being attributed to the variability in methodological factors with the present study.
\end{abstract}

Keywords: Biochemistry, Hematology, Rabbits, Rectal temperature, Systolic blood pressure.

\section{Introduction}

In the veterinary literature that covers pet rabbit medicine, many of the laboratory reference values come from studies in laboratory rabbits. These studies are carried out on breeds (mostly on the New Zealand White rabbit) of rabbits that not correspond with the constellation of breeds and mixed-breeds of pet rabbits that come to the daily clinic, samples are obtained by methods that differ from methods employed in the pet clinic practice, and husbandry between laboratory and pet rabbits is far different. It is known that laboratory values in rabbits and other species differ according to the breed, sampling method, stress, immobilizing agents, haemolysis, husbandry, etc (Fox et al., 1970; McLaughlin and Fish, 1994).

According to the sampling method there are several venipuncture collection sites in rabbits that have been used in laboratory animals but many of these sites are not routinely employed in the daily clinic for various reasons. Venipuncture of the jugular vein usually requires sedation and the dewlap may interfere in the extraction. The marginal veins of the ear and the cephalic vein are often good options for inserting an intravenous catheter (the author prefers the marginal veins of the ear because it is more difficult for the rabbit to remove it without an elizabethan collar), but blood extractions are difficult due to the restraint of the animal and to the small vein size, except in large breeds. Although avascular necrosis of the pinna has been described widely in the literature after puncturing the central artery of the ear (Melillo, 2007; Graham and Mader, 2012) it has only been observed by the author on rare occasions and is a good collection site for arterial blood gas analysis in pet rabbits (Ardiaca et al.,
2013). Blood extraction from the cranial vena cava and cardiocentesis may be dangerous to the rabbit and requires deep sedation, so the author only recommends this sites for euthanasia or in emergency situations in which the risk / benefit for the animal has been weighed.

In the author's opinion, as well as of other authors (Melillo, 2007; Graham and Mader, 2012), the lateral saphenous vein is the most easily accessible venipuncture site in non-sedated rabbits, allowing to extract a sufficient blood volume for routine blood tests with an adequate restraint of the rabbit.

In some difficult cases, such as animals in critical condition, it would be helpful to warm the area over the vessel to promote vasodilation, facilitating successful venipuncture and collection of blood. In some cases, especially in the case of the central artery of the ear, the author employs a local anesthetic cream ${ }^{\mathrm{a}}$ prior to the venipuncture (Cooke, 2000) because it prevents a sudden movement of the member at the moment of introducing the needle through the skin.

The importance of this work lies in the scarcity of bibliography concerning laboratory references taken in healthy pet rabbits.

\section{Materials and Methods}

\section{Animals}

In the first part of the study, prospective data from 86 healthy pet rabbits were employed to establish reference intervals for urinalysis, blood biochemistry, hematology, venous gasometry, rectal temperature and systolic blood pressure (SBP). Rabbits were included in the study when an informed client consent was obtained, the rabbits had undergone an unremarkable full physical examination, the medical history had no 
reportable health problems, and, if there were other complementary tests that did not reveal evident alterations. The study animals consisted of 8 sexually intact females, 31 neutered females, 20 sexually intact males and 27 neutered males. The ages ranged from 5 months to 10 years.

The reference intervals for urinalysis were obtained from 40 rabbits, from 60 for blood biochemistry, from 54 for hematology, from 47 for gasometry and rectal temperature, and from 38 for SBP.

\section{Blood data, rectal temperature and systolic blood} pressure collection

Blood samples for hematology and blood biochemistry were obtained from one saphenous vein in awake rabbits employing a little amount of alcohol $70 \%$ over the site of venipuncture. Lipemic, hemolyzed or clotted blood samples were discarded. The amount of blood extracted never exceeded $0.5 \%$ of the animal weight in grams, expressed in milliliters, i.e. $0.5 \mathrm{ml}$ per $100 \mathrm{~g}$ of body weight, which has been considered a safe amount in a healthy rabbit (Cooke, 2000; Melillo, 2007; Wesche, 2014).

For hematology, blood in EDTA tubes was analyzed in a cell counter (MS4 Vet; Melet Schloesing) in less than 30 minutes after extraction. For biochemistry, blood in lithium heparin tubes was centrifuged immediately after extraction and analyzed in less than two hours with an automated analyzer (Chemray 120; Rayto).

For venous gasometry, a sample of at least $70 \mu \mathrm{l}$ of blood from the other saphenous vein was obtained with a gasometry syringe ( $1 \mathrm{ml} / 25 \mathrm{IU}$ dry balanced heparin; Westmed) and analyzed in a gasometer (ABL80Basic FLEX; Radiometer) immediately. Rectal temperature was measured in all rabbits that undergone a venous gasometry analysis with a digital thermometer (Thermoval rapid flex; Hartmann) as follows; the owner or an operator supported the rabbit standing with its four legs on the exploration table and a second operator inserted the thermometer into the rectum to a distance of approximately $3 \mathrm{~cm}$.

To assess the SBP, the mean value of at least 3 measurements by doppler ultrasonography (Vettex Uni, $8 \mathrm{mhz}$ flat probe; Huntleigh) in the forearm were obtained using a cuff with a width of $40 \%$ of the circumference of the limb, located proximally to the elbow, and shaving the palmar zone proximal to the first phalanx to place the probe.

\section{Urinalysis performance}

Urine samples were collected by manual expression of the urinary bladder (Fig. 1) on a surface cleaned without quaternary ammonium disinfectants nor chlorhexidine, as the dipstick manufacturer recommends.

Urine samples $(n=43)$ were centrifuged at 9,800 rpm for 45 seconds (StatSpin $®$ VT, Iris Sample Processing).
In the supernatant, a dipstick (10 Combur UX® test; Roche) was processed with an automatic device (Urisys ${ }^{\circledR}$; Roche). Urinary sediment was evaluated by light microscopy (40X) without stain it (Fig. 2). Urine samples with active sediment were discarded. Urine sand-like crystals were analyzed by infrared spectroscopy in three sediment samples in which no other crystals were observed, because they could not be classified according to their appearance.

\section{Statistical analysis}

Reference intervals with $90 \%$ confidence were obtained employing the software Reference Value Advisor (Geffré et al., 2011). The reference intervals obtained were compared with some present in the bibliography. Due to the lack of information concerning the laboratory methods used in many of the evaluations present in the bibliography that were compared with the results obtained in the present study, the comparison between reference values was considered complex; values that differ by more than $30 \%$ from the value of the reference interval obtained in the present work were noticed.

\section{Results and Discussion}

Values that differ by more than $30 \%$ with all the reference intervals evaluated in the bibliography are alkaline phosphatase (ALP), aspartate aminotransferase (AST), gamma-glutamyl transferase (GGT) and glucose.

Urine sand-like crystals were classified as amorphous calcium carbonate (Fig. 2).

Laboratory reference intervals were established in a group of 86 healthy rabbits (Tables 1 and 2). The results of the present study show that differences of more than $30 \%$ with reference intervals present in the bibliography were observed only in the blood biochemistry and urinalysis. The disparity between published reference values is well known, therefore it is generally recommended to establish a reference interval for each laboratory (Tvedten and Thomas, 2012).

The reference interval obtained for the glucose value in this work $(112-231 \mathrm{mg} / \mathrm{dL}(6.22-12.82 \mathrm{mmol} / \mathrm{L}))$ is higher than in the literature evaluated. Glucose can increase artifactually in stressful situations in rabbits. The stress that a rabbit undergoes during the trip to the veterinary clinic and by management necessary for the extraction of blood could explain this result and that of lactate dehydrogenase (LDH) value (53-239 IU/L), which is elevated with respect to Wesche (2014). However, other indicators of stress such as total white blood cell count, creatine kinase and AST (McLaughlin and Fish, 1994) did not showed elevations known to be produced by stress in the present work if this values are compared with some published reference intervals (Table 1). 
Table 1. Reference interval obtained for hematology $(n=54)$, biochemistry $(n=60)$ and systolic blood pressure $(n=38)$ in healthy rabbits.

\begin{tabular}{|c|c|c|c|c|}
\hline BIOCHEMISTRY & $\begin{array}{l}\text { Reference interval } \\
\text { (90\% Confidence) }\end{array}$ & Varga, 2014 & Wesche, 2014 & Melillo, 2007 \\
\hline Magnesium mg/dL (mmol/L) & $1.9-3.2(0.95-1.6)$ & $0.8-1.2(\mathrm{a})$ & - & - \\
\hline $\operatorname{ALP}(I U / L)$ & $42-120$ & $10-70 *$ & - & $12-96$ \\
\hline ALT (IU/L) & $19-68$ & $25-65$ & $27-72$ & $45-80$ \\
\hline AST (IU/L) & $6-38$ & $10-98 *$ & $10-78^{*}$ & $35-130 *$ \\
\hline CPK (IU/L) & $93-473$ & - & $59-175^{*}$ & $140-372$ \\
\hline GGT (IU/L) & $8-21$ & $0-7 *$ & $0-5^{*}$ & $0-7 *$ \\
\hline LDH (IU/L) & $53-239$ & - & $28-102 *$ & - \\
\hline Bile acids $(\mu \mathrm{mol} / \mathrm{L})$ & 26-34 & $<40$ & - & $<40$ \\
\hline Total bilirubin mg/dL $(\mu \mathrm{mol} / \mathrm{L})$ & $0-0.4(0-6.84)$ & $0.2-0.5(3.4-8.5)$ & $0.2-1(2.6-17.1)^{*}$ & $0-0.7(0-11.97)^{*}$ \\
\hline Glucose mg/dL (mmol/L) & $\begin{array}{c}112-231 \\
(6.22-12.82)\end{array}$ & $\begin{array}{c}76-141 \\
(4.2-7.8)^{*}\end{array}$ & $\begin{array}{c}99-148 \\
(5.5-8.2)^{*}\end{array}$ & $\begin{array}{c}75-155 \\
(4.16-8.6)^{*}\end{array}$ \\
\hline Total protein $\mathrm{g} / \mathrm{dL}(\mathrm{g} / \mathrm{L})$ & $6-7.6(60-76)$ & $5.4-7.5(54-75)$ & $4.9-7.1(49-71)$ & $5.4-7.5(54-75)$ \\
\hline Albumin $g / d L(g / L)$ & $3.1-4.3(31-43)$ & $2.7-5(27-50)$ & $2.7-5(27-50)$ & $2.7-5(27-50)$ \\
\hline Globulin $(\mathrm{g} / \mathrm{L})$ & $2.1-3.7(21-37)$ & $1.5-2.7(15-27)$ & $1.5-3.3(15-33)$ & $1.5-2.7(15-27)$ \\
\hline Cholesterol mg/dL (mmol/L) & $6-65(0.16-1.68)$ & $12-116(0.3-3)^{*}$ & 4-77 (0.1-2) & $10-80(0.26-2.07)$ \\
\hline Triglycerides mg/dL (mmol/L) & $22-188(0.25-2.12)$ & $124-156(1.4-1.76)$ & $124-156(1.4-1.76)$ & - \\
\hline Amylase (IU/L) & $82-343$ & $200-500 *$ & $212-424$ & $200-400$ \\
\hline Lipase (IU/L) & $38-210$ & - & - & - \\
\hline HAEMATOLOGY & $\begin{array}{l}\text { Reference interval } \\
\text { (90\% Confidence) }\end{array}$ & Varga, 2014 & Wesche, 2014 & $\begin{array}{c}\text { Graham and Mader, } \\
2012 \\
\end{array}$ \\
\hline Hematocrit (\%) & $33-46$ & $33-48$ & $30-40$ & $33-55$ \\
\hline RBC (x106/ul) & $4.6-7.4$ & $4-7$ & $5.1-7.6$ & $5.1-7.9$ \\
\hline WBC (x103/ul) & $4.1-10.8$ & $5-12$ & $5.2-12.5$ & $5.2-12.5$ \\
\hline Haemoglobin (g/dL) & $10.1-15.1$ & $10-15$ & $10-15$ & $10-17.4$ \\
\hline $\operatorname{MCV}(\mathrm{fl})$ & $59.5-69.3$ & $60-75$ & $60-69$ & $57.8-66.5$ \\
\hline $\mathrm{MCHC}(\mathrm{g} / \mathrm{dL})$ & 29.3-37.9 & 34.5 & $30-35$ & 29-37 \\
\hline $\mathrm{MCH}(\mathrm{pg})$ & $18.5-24.5$ & $19-23$ & $19-22$ & $17.1-23.5$ \\
\hline Platelets (x103/ul) & $134-567$ & $250-600$ & $250-650$ & $250-650$ \\
\hline $\mathrm{SBP}(\mathrm{mmHg})$ & $75-134$ & - & - & - \\
\hline
\end{tabular}

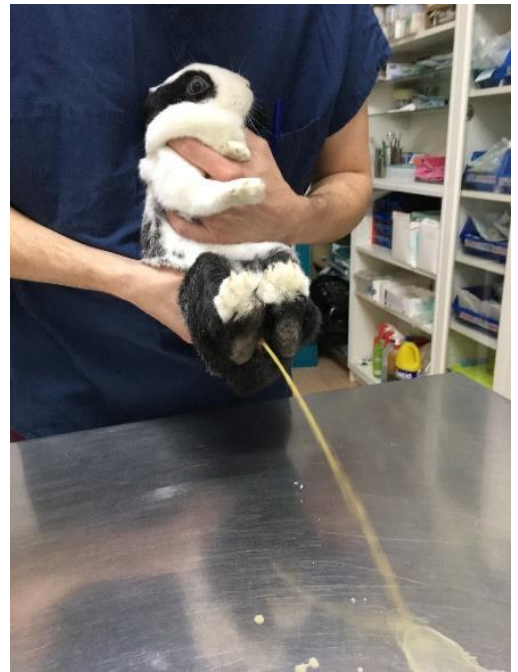

Fig. 1. Urine sample collection from a rabbit by manual expression of the urinary bladder.

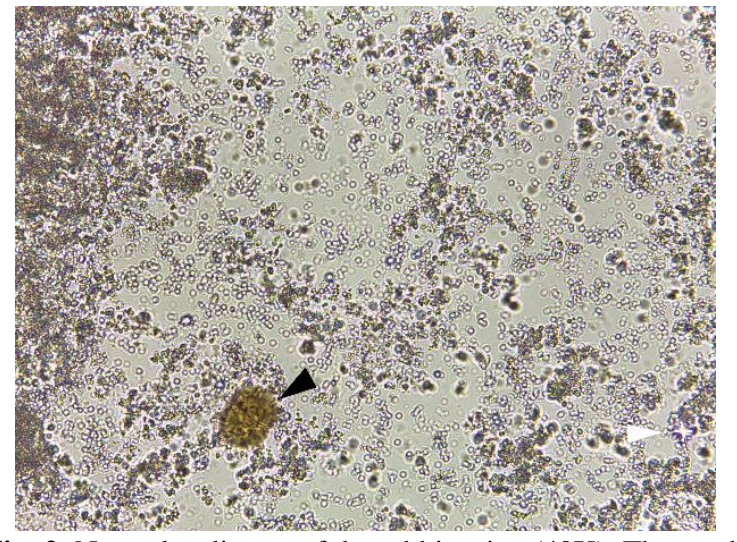

Fig. 2. Normal sediment of the rabbit urine (40X). The sandlike material are amorphous crystals of calcium carbonate (analyzed by infrared spectroscopy). In the urinary sediment of rabbits we can also find a moderate amount of calcium carbonate dihydrate crystals (black arrowhead) and, occasionally, calcium oxalate crystals (white arrowhead). 
Table 2. Reference range obtained for urinalysis $(n=43)$ and acid-base balance $(n=47)$ in healthy rabbits and comparison with other reference values present in the literature.

\begin{tabular}{|c|c|c|c|c|}
\hline URINALYSIS & $\begin{array}{l}\text { Reference interval } \\
(90 \% \text { confidence) }\end{array}$ & Varga, 2014 & Wesche, 2014 & Melillo, 2007 \\
\hline $\mathrm{pH}$ (strip) & $8-9$ & $7.6-8.8$ & $7.5-9$ & $7.5-9$ \\
\hline USG (strip) & $1010-1015$ & - & - & - \\
\hline Leucocytes (strip) (uL) & $0-25$ & - & 0 & - \\
\hline Nitrites (strip) & neg & - & - & - \\
\hline Proteins (strip) mg/dL (g//L) & $0-30(0-3)$ & 0 -traces* & 0 -traces* & - \\
\hline $\begin{array}{l}\text { Glucose (strip) } \mathrm{mg} / \mathrm{dL} \\
(\mathrm{mmol} / \mathrm{L})\end{array}$ & 0 & 0 -traces & 0 -traces & - \\
\hline Ketones (strip) (mg/dL) & $0-15$ & - & 0 & 0 \\
\hline $\begin{array}{l}\text { Urobilinogen (strip) } \mathrm{mg} / \mathrm{dL} \\
(\mathrm{mmol} / \mathrm{L})\end{array}$ & $0-1(0-1.7)$ & - & - & - \\
\hline $\begin{array}{l}\text { Bilirubin (strip) } \mathrm{mg} / \mathrm{dL} \\
(\mathrm{mmol} / \mathrm{L})\end{array}$ & 0 & - & 0 & - \\
\hline Erythrocytes (strip) (uL) & 0 & - & 0 & - \\
\hline Sediment & $\mathrm{ACC}, \mathrm{CCD}, \mathrm{CO}$ & $\mathrm{CC}, \mathrm{CO}, \mathrm{STR}$ & CCM, AnCC, STR & - \\
\hline GASOMETRY (venous blood) & Reference interval & Ardiaca et al., 2013 & Wesche, 2014 & Melillo, 2007 \\
\hline $\mathrm{pH}$ & $7.23-7.56$ & $7.25-7.53$ & - & - \\
\hline $\mathrm{pCO} 2(\mathrm{mmHg})$ & $28.5-50.7$ & $28.9-52.9$ & - & - \\
\hline $\mathrm{pO} 2(\mathrm{~mm} / \mathrm{Hg})$ & $18-48.3$ & - & - & - \\
\hline $\mathrm{HCO} 3-(\mathrm{mmol} / \mathrm{L})$ & $15.8-30.2$ & $17-32.5$ & $16-32$ & - \\
\hline Base excess (mmol/L) & $-8.8-5.7$ & $-10-8$ & - & - \\
\hline Anion gap (mmol/L) & $8.8-26.4$ & $11-26$ & - & - \\
\hline Sodium $(\mathrm{mmol} / \mathrm{L})$ & $139-149$ & $136-147$ & $130-155$ & $138-150$ \\
\hline Potassium (mmol/L) & $3.8-6.1$ & $3.4-5.7$ & $3.3-5.7$ & $3.5-6.9$ \\
\hline Chloride (mmol/L) & $96-113$ & 93-113 & $92-120$ & - \\
\hline Lactate $(\mathrm{mmol} / \mathrm{L})$ & $2-10(a)$ & $2.1-15.2(b)$ & - & - \\
\hline Rectal temperature $\left({ }^{\circ} \mathrm{C}\right)$ & $37.4-39.6$ & - & - & - \\
\hline
\end{tabular}

In the author's opinion stress may have caused minimal changes in the value of glucose and LDH, but these values can be assumed as normal if the same methodology is employed.

The reference interval obtained for the ALP value in this work (42-120 IU/L) is higher than in the literature evaluated. It is possible that the wide range of ages of the animals included in the study (5 months to 9 years) explains this fact because the ALP value is known to be higher in young rabbits (Melillo, 2007; Varga, 2014; Wesche, 2014) and the results have not been evaluated by ages.

The reference interval obtained for the GGT value in this work (8-21 IU/L) is higher than in the literature evaluated. Elevated GGT in pet rabbits has been associated with hepatic lipidosis, hepatic coccidiosis and could be an indicator of biliary stasis as in other species (Melillo, 2007; Wesche, 2014). In the present work the rabbits were considered healthy for meeting the inclusion criteria and a literature search failed to find causes by which the GGT value can be elevated artefactually in rabbits, so the reference interval obtained for the GGT value in the present work can be considered as valid if the same methodology is used.

The reference interval obtained for the AST value in this work (6-38 IU/L) is lower than in the literature evaluated. A literature search failed to find causes by which the AST value can be artefactually low in rabbits, so the reference interval obtained for the AST value in the present work can be considered as valid if the same methodology is used. A literature search failed to find references for rectal temperature $\left(37.4-39.6^{\circ} \mathrm{C}\right)$ and systolic blood pressure $(75-134 \mathrm{mmHg})$ values in healthy unanesthetized pet rabbits.

\section{Conclusion}

Laboratory reference intervals of importance in the daily clinical practice of pet rabbits were reported, including rectal temperature $\left(37.4-39.6^{\circ} \mathrm{C}\right)$ and systolic blood pressure (75-134 mm/Hg), previously unreported in pet rabbits.

\section{Conflict of interest}

The authors declare that there is no conflict of interests. 


\section{References}

Ardiaca, M., Bonvehí, C. and Montesinos, A. 2013. Point-of-Care Blood Gas and Electrolyte Analysis in Rabbits. Vet. Clin. North Am. Exot. Anim. Pract. 16, 175-195.

Ardiaca, M., Dias, S., Montesinos, A., Bonvehi, C., Barrera, S. and Cuesta, M. 2016. Plasmatic 1-lactate in pet rabbits: association with morbidity and mortality at 14 days. Vet. Clin. Pathol. 45(1), 116123.

Cooke, S.W. 2000. Clinical chemistry. In: Manual of rabbit medicine and surgery. $1^{\text {st }}$ edn. Eds P.A. Flecknell. British Small Animal Veterinary Association, Gloucester, pp: 25-32.

Fox, R.R., Laird, C.W., Blau, E.M., Schultz, H.S. and Mitchell, B.P. 1970. Biochemical parameters of clinical significance in rabbits. I. Strain variations. J. Hered. 61, 261-265.

Geffré, A., Concordet, D., Braun, J.P. and Trumel, C. 2011. Reference Value Advisor: a new freeware set of macroinstructions to calculate reference intervals with Microsoft Excel. Vet. Clin. Pathol. 40(1), 107112.
Graham, J.E. and Mader, D.R. 2012. Basic approach to veterinary care. In: Ferrets, rabbits and rodents. Clinical medicine and surgery. $3^{\text {rd }}$ edn. Eds K.E. Quesenberry and J.W. Carpenter. Elsevier, Missouri, pp: 174-182.

McLaughlin, M.R. and Fish, R.E. 1994. Clinical biochemistry and hematology. Sources of variation. In: The biology of the laboratory rabbit. $2^{\text {nd }}$ edn. Eds P.J. Manning, D.H. Ringler and C.E. Newcomer. Academic Press, San Diego, pp: 112.

Melillo, A. 2007. Rabbit Clinical Pathology. J. Exot. Pet Med. 16, 135-145.

Tvedten, H. and Thomas, J.T. 2012. General laboratory concepts. In: Small animal clinical diagnosis by laboratory methods. $5^{\text {th }}$ ed. Eds M.D. Willard and H. Tvedten. Elsevier Saunders, Missouri, pp: 1-11.

Varga, M. 2014. Clinical pathology. In: Textbook of rabbit medicine. $2^{\text {nd }}$ ed. Eds M. Varga. Butterworth-Heinemann, Edinburg, pp: 111-136.

Wesche, P. 2014. Clinical pathology. In: BSAVA manual of rabbit medicine. $1^{\text {st }}$ edn. Eds Meredith, A. and Lord, B. British Small Animal Veterinary Association, Gloucester, pp: 124-137. 